\title{
Shifting paradigms for fashion: from total to global to smart consumer experience
}

\author{
HaeJung Kim*, Soo-Kyoung Ahn and Judith A Forney
}

\author{
* Correspondence: HJKim@unt.edu \\ College of Merchandising, \\ Hospitality \& Tourism, University of \\ North Texas, 1155 Union Circle, \\ \#311100, Denton, TX 76203-5017, \\ USA
}

\begin{abstract}
Emergence of a global techno-economic system is challenging academia and the fashion industry. Consumers, the retail industry and business strategies are strategically contributing to the changing fashion paradigm, which is shifting from the Total (TCE), to Global (GCE) and to Smart Consumer Experience (SCE) concepts. The consumer experience is a pervasive value orientation that is transforming how consumers think, gain information, and make decisions about consumption activities to maximize their total experience value. Moreover, the experiences, products and services that consumers seek are being defined with a global and smart perspective that is made possible by boundary-free access to information and sourcing of products and services. Specifically, the smart consumer experience advocates consumer participation by leveraging the power of communities and networks and enabling consumers to influence retail businesses and co-create future marketspace values. This phenomenon has implications for fashion consumers and fashion retail industry business strategies since fashion is an emulated behavior.
\end{abstract}

Keywords: Consumer experience; Fashion; Global; Retail; Technology

\section{Introduction}

Fashion represents one of the most complicated concepts related to human social behavior. Consumers buy fashionable products more for what they mean than for their literal utility (Hirschman and Holbrook, 1982a, b) and use fashion to send visual identify cues to others (Holman, 1980; O'Cass and McEwen, 2004; Solomon, 1983). Moreover, consumers use fashion products to improve their personal image and to present a form of recognition in a social environment (Miller et al., 1993). Fashion acquires symbolic meaning through a socialization process (Hirschman and Holbrook, 1982a); thus social relationships are needed to spread fashion.

As a dynamic phenomenon, fashion undergoes frequent and regular changes in various cultural, social, politics, economic, and aesthetic milieu (Evans, 1989) whereby different fashion trends emerge, become recognized, get adopted, and then disappear (Cholachatpinyo et al., 2002). A fashion phenomenon occurs when a product corresponding with a current theme is adopted by a large number of consumers over a specific period of time (Rogers, 1983).

The rapid evolution of information and technology and their revolutionary impact on the marketplace and consumers has yet to be examined in the context of fashion. For instance, on the Lululemon website consumers can join an online brand buzz 
(i.e., "the sweat life") by uploading photos showing them wearing the brand's products. This consumer-created content has generated over two million page views on Lululemon's website and one million "likes" on its Instagram page (Binkley, 2013). Similarly, Pinterest, Instagram, Tumblr and Facebook serve as social platforms to connect consumers with brands where consumers share and engage in social activities provided by these social media during shopping (Cowan, 2012). However, a pragmatic conceptualization of this radical and dynamic paradigm shift of how consumers interact in the marketplace with products, brands and information is missing for fashion.

Global 24/7/356 information access through digital platforms, has transitioned traditional marketplaces into marketspaces where content, context, and infrastructure are recreating the concept of value (Rayport and Sviokla, 1994). Consumer-centric businesses are seeking innovative strategies to fulfill increasing consumer demands with diverse interactive relationship such as consumer-to-consumer $(\mathrm{C} 2 \mathrm{C})$ and consumer to business $(\mathrm{C} 2 \mathrm{~B})$ in addition to traditional business-to-consumer (B2C). Consumers constantly seek convenience, choice, excellent service, information, and enjoyable experiences through reasoning, decision-making, problem-solving, and evaluation (Kim, 2012). Information access empowers consumers to be creators and influencers in the global community where they are able to capitalize on their social structures, relationships and knowledge in marketspaces (Huang et al., 2013). These empowered consumers form borderless clusters with new social meaning and economic impact in the global technology interface (Kearsley and Shneiderman, 1998). In doing so consumers maximize the totality of their experience (i.e., total consumer experience), optimize their experience on global scale (i.e., global consumer experience), and co-create experience value through advanced technology and information (i.e., smart consumer experience). This transformation of the consumer experience is requisite to understand emerging trends and to propose a collaborative and interdisciplinary fashion research paradigm that can lead to better understanding, creation, and management of consumer experiences in the fashion industry.

The purpose of this conceptual study is to examine the fashion from the perspective of three paradigm shifts that progressed from the Total Consumer Experience (TCE) to the Global Consumer Experience (GCE) and most recently to the Smart Consumer Experience (SCE) archetype. To organize understanding of this phenomenon, and to offer suggestions for research, we first examine the consumer experience by proposing the Total (TCE), Global (GCE) and Smart consumer experience (SCE) concepts derived from the pioneering concept of the experience economy (Pine and Gilmore, 1999), service-dominant logic (Vargo and Lusch, 2004, 2006, 2008), consumer culture theory (Arnould and Thompson, 2005), social capital theory (Putnam, 1995) and digital engagements (Csikszentmihalyi, 1990, 1997; Mollen and Wilson, 2010) concepts. Second, we provide evidence of how consumers and the retail industry are shifted their business models for fashion. Such theoretical and practical contributions are of interest to researchers in consumer behavior, marketing and service management. Finally, we will discuss the need for producing meaningful tools and guiding principles to support industry practice.

\section{Theoretical background}

Total Consumer Experience (TCE)

Consumer experience is defined as a sensation that occurs within an individual when a business intentionally and successfully uses services as a stage and goods as props to 
connect at a physical, emotional, intellectual, and/or spiritual level (Pine and Gilmore, 1999). The product evolution from commodities to goods, services, and experiences is through transformation by memorable events or interactions where conventional utilitarian consumer-business transactions are translated into meaningful and value-added consumer benefits (Pine and Gilmore, 1999). In the retail industry, experience transformation is found in the trend toward "experiential retailing" where intangible, hedonic, and symbolic aspects of "shopper-tainment" and "retail-tainment" become key motivators of product purchases (Hirschman and Holbrook, 1982a; Kim et al., 2007; Oliver et al., 1997).

Consumers constantly have an experience, which originates from a set of interactions between a customer and a product, a company, or part of its organization, and when they purchase and use a product or service (Vehoef et al., 2009). The consumer experience centers the functionality of which emotional and sensory experience from all the smells, sounds, sights, tastes and textures of the goods or services are integrated with the environmental experience from a physical or virtual store (Berry et al., 2002). The consumer experience construct is holistic in nature and involves the customer's cognitive, affective, emotional, social, and physical responses to the retailer (Vehoef et al., 2009). Thus the consumer experience is the sum of internal and subjective responses to any direct or indirect contact with a company (Meyer and Schwager, 2007; Vehoef et al., 2009). Direct contact generally occurs during activities of purchase, use, and service that are usually initiated by the customer. Indirect contact most often involves unplanned encounters with representations of a company's products, service, or brand and takes the form of word-of mouth recommendations or criticisms, advertising, new reports, reviews, and so forth (Meyer and Schwager, 2007).

In fashion business perspective, the Total Consumer Experience (TCE) refers to strategic business logic that portrays creating superior consumer experience in conjunction with transactions with customers as a source of competitive advantage for a company. In fashion consumer standpoint, the TCE stands for a comprehensive experience generated through direct and indirect relationships between the customer and business that provides an engrossing environment for a consumer's involvement and experience. Thus, TCE must balance both physical and emotional elements along all the stages of the customer experience and value chain (Mascarenhas et al., 2006). The resulting TCE has an internal or subjective component as well as an external or objective component related to distinct product offerings along all points of the production-consumption chain (Mascarenhas et al., 2006). TCE satisfies consumers' emotional or expressive desires as well as their rational or functional needs (Kim et al., 2007). TCE features provisions for: (1) providers anticipating and fulfilling customer needs and wants better than competitors; (2) a maximization of the totality of the consumer experience; (3) a real emotional experience that offers meaning, value, entertainment, friendly and caring service, belongingness, brand community, and a memorable experience; (4) interactional experiences arising from the value-adding interfaces between customer involvement and producer participation; and (5) experiences as engaging memories. Much of experiential consumption research emphasizes emotions and contextual, symbolic and nonutilitarian aspects of consumption where value resides not in the object of consumption but in the experience of consumption (Berry and Carbone, 2007; Hirschman and Holbrook, 1982b). Refer to Figure 1. 


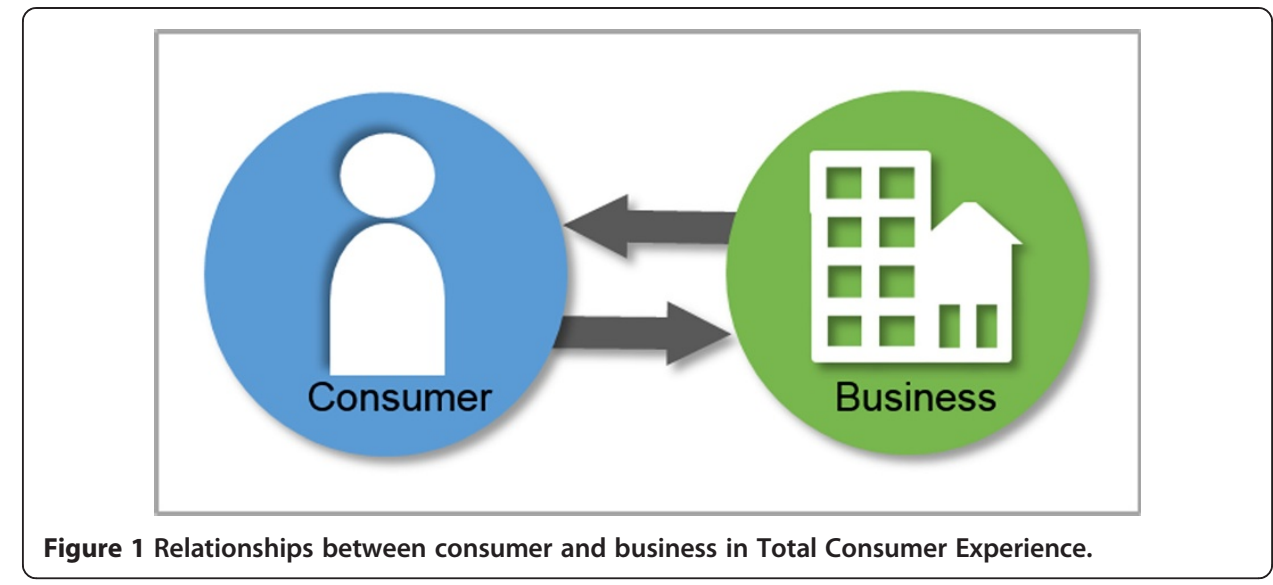

Global Consumer Experience (GCE)

Prevailing and emerging market trends that include significant changes in demographic characteristics of global populations, convergence and divergence of consumer cultures, and information access through technology advancement, are leading consumers to demand optimal consumption experiences in exchange for investments of time, money and energy. The paradigm of TCE expands to the inclusive paradigm of the Global Consumer Experience (GCE) which describes global experience as the core purpose of transaction and provides a theoretical understanding of how businesses, consumers, and other market actors co-create value through their interaction with each other on a global scale. Thus, GCE extends experience that allows a borderless transaction which is free from spatial-temporal restrictions supported by advanced technology and an interaction with the consumption environment including a business, other consumers, cultures, ideologies, and technologies by sharing information and experience with them.

The GCE paradigm recognizes new intellectual inquiry that is grounded within a meso or macro level of theoretical orientation. From a modern positivist perspective, managerial relevance is explained in terms of a rational choice paradigm and its corresponding focus on purchase behavior in the micro level approach (Arnould and Thompson, 2005). From this perspective, many disciplinary theories have expanded into multidisciplinary frameworks for understanding knowledge (i.e., Consumer Social Learning Theory, Theory of Reasoned Action, and Theory of Planned Behavior) and they can be applied to understanding the consumer experience. While anecdotal evidence underscores many of the market trends previously mentioned, there is a need to develop macro level approaches that better inform research and practice regarding global consumer experiences.

Consumer culture theory (CCT) explores how consumers actively rework and transform symbolic meanings encoded in advertisements, brands, retail settings, or material goods to manifest their particular personal and social circumstances and to further their identity and lifestyle goals (Grayson and Martinec, 2004; Holt, 2002; Kozinets, 2001, 2002; Mick and Buhl, 1992; Peñaloza, 2000, 2001; Ritson and Elliott, 1999; Scott, 1994). Researchers have applied CCT to explain consumer behavior prior to globalization or IT advancement. CCT encourages investigation of contextual, symbolic, and experiential aspects of consumption as they unfold across a consumption cycle that includes acquisition, consumption, possession, and disposition processes as well as analysis of these phenomena from macro-, meso-, and micro-theoretical perspectives (Belk, 1988; Belk et al., 
1988; Hirschman and Holbrook, 1982b; Holbrook, 1987; McCracken, 1986; Mick, 1986). While CCT has advanced consumer behavior knowledge by clarifying socio-cultural processes and structures related to the GCE paradigm, more diverse theories need to be applied to explain consumers behaviors and experiences in the context of globalization.

GCE is drawn from an amalgamation of fashion encounters influenced by the advances in technology on communication and the infusion of entertainment and media as major contributors to optimal experiences. GCE has distinctive features: (1) while TCE focuses on the relations between consumer and business, GCE broadens its viewpoint to interactions (or sharing) between consumer and environment including businesses, other consumers, cultures, ideologies, and technologies beyond spatial-temporal restrictions; (2) TCE aims at consumers' memorable experiences with these relations, GCE, however, guides physical, emotional, intellectual, or spiritual transformations within a consumer (Pine and Gilmore, 2001); and (3) GCE revitalizes core analytic constructs of brand loyalty (Fournier, 1998; McAlexander et al., 2002; Muñiz and O'Guinn, 2000), consumer lifestyles (Holt, 1997; Thompson, 1996), retail experiences (Kozinets et al., 2004; Peñaloza, 2001), advertising information processing (Escalas and Stern, 2003), customer satisfaction (Fournier and Mick, 1999), and consumer involvement (Coulter et al., 2003). Refer to Figure 2.

\section{Smart Consumer Experience (SCE)}

Consumers who are empowered, networked and engaged in digital environments create, share, and demand a smart experience which capitalizes on their social structure, relationships, and knowledge. Smart consumers engage in digital environments not only for information seeking and sharing but also for receiving a sense of belongingness, finding connections and building social networks (Andrews, 2002; Zhang and Hiltz, 2003). Recently, social shopping was identified as a new model of e-commerce (Lee and Lee, 2012) based on this collaborative virtual consumption phenomenon. With an expanded number of social media sites and increased social-media adoption,

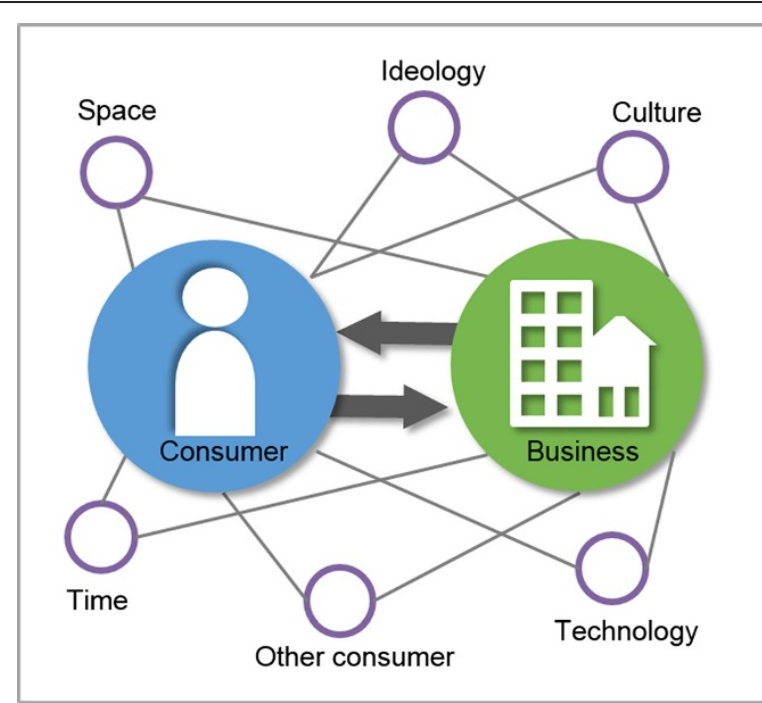

Figure 2 Interactions between consumer and business in Global Consumer Experience. 
global social commerce revenue is projected to be 20 billion U.S. dollars in 2014 and grow to 30 billion U.S. dollars by 2015 (Statista.com, 2014). Social commerce interface is enabled by smart technologies such as GPS, interactive tools, and in-store technology along with applications such as pinning, personalized searching apps, and mobile wallet. In 2013, the annual growth rate of subscribers compared to 2012 was estimated to be $44 \%$ for smartphones and $125 \%$ for tablets (ABI Research, 2013). The popularity of mobile devices based on geo-location technology is accelerating SoLoMo (Social-LocalMobile) technology and application.

The SoLoMo platform advances the concept of Smart Consumer Experience (SCE) that suggests facilitating and enhancing value co-creation is the strategic capability central to a business competitive advantage. GCE and SCE are not considered in this study to present two end of single continuum. Instead we view them as two potentially orthogonal types of experience, which suggest consumer experiences are best conceived as offering some degree of both. GCE has an obvious different nature in terms of the transaction between consumer and business, while SCE does not always require transaction. However SCE emphasizes that intelligent consumers play diverse roles in the consumption environment as principle agents of transaction and interaction. In fact, smart consumers become culture creators, merchandise curators, product and service evaluators, brand advisors, brand fans as well as buyers by employing smart devices or software that are uniquely tailored for each consumer.

The concept of co-creating value stands for assisting consumers in co-constructing and engaging in superior experiences (Karpen et al., 2012). The managerial and theoretical concept of value co-creation is oriented to a service-dominant (hereafter S-D) logic (Vargo and Lusch, 2004, 2006, 2008) where the superior value co-creation and the focus on intangible resources and relationships are at the core of competitive advantage in a business. When consumers are viewed as an integral part of value creation, the role of business becomes that of a facilitator, supporter, and co-constructor of value rather than a supplier of value (Firat and Dholakia, 2006; Vargo and Lusch, 2008). The flexibility and fluidity inherent in the SoLoMo environment enables smart consumers to transfer resources from one channel to another. Facebook fans often transfer the trust established through their social relationships with the brand and other fans, and formulate a positive attitude toward the brand's online website, where the actual transactions occur. In retailing, these social channel conversions and resource transfers develop a complex multi-channel platform. Recent reports of consumers' increased multi-channel shopping suggest a new paradigm of integrated retailing has emerged. For example in a survey of consumer expectations regarding integrated shopping, 82 percent of respondents would shop again at a retailer who accepted in-store returns for online purchase, 73 percent were more likely to become a repeat customer if a store offered in-store pickup of online orders, and 59 percent indicated ease of website navigation was the most important factor for following through with an online purchase (http://www. webpronews.com/u-s-consumers-expect-integrated-retail-2012-05). In fact, consumers are changing their purchasing behaviors by integrating online shopping activities with visits to a retailer's physical, brick and mortar storefront. This integrated shopping experience is referred to as omni-channel retailing (Lewis, 2014).

In order to understand consumer and business dynamics in SCE, specifically to determine how SCE is a transformative paradigm for the fashion industry, this study adopts 
the concept of Social Capital for a macro approach, and the concept of Digital Engagement for a micro approach. Social capital refers to "the features of social organization, such as networks, norms, and social trust that facilitate coordination and cooperation for mutual benefit" (Putnam, 1995 p. 66). Due to its relational supremacy, social capital enhances professional practice and increases the capability for knowledge collection within a society (Wasko and Faraj, 2005). Social capital is studied in diverse business contexts such as the company environment (Gooderham et al., 2010), social networks (Valenzuela et al., 2009; Chang and Chuang, 2011), brand-based community (Muñiz and Schau, 2005), and individuals' identities within a group (Bagozzi, 2000) to gauge the social and economic impact of social capital (Kim et al., 2014).

In the context of the SCE paradigm, social capital consists of three dimensions: (1) structural capital as a collective's ability to examine individual action in a collective work; (2) cognitive capital as the resources providing shared meanings within a group; and (3) relational capital as identification within the group, trust in others, and commitment to participate in the collective and conform to the cooperative norms (Wasko and Faraj, 2005).

Smart consumers are engaged in digital environment not only for information seeking and sharing but also for a sense of belongingness, find connections and build social networks (Andrews 2002; Zhang and Hiltz 2003). These social interactions often refer to relationships of structural capital (Wellman et al., 1996), which are related to engagement ties (Wellman et al., 1996). The active and positive interaction among smart consumers within a social structure increases an individual's satisfaction, which positively affects digital engagement in SCE (Kim et al., 2014; Langerak et al., 2004). Cognitive capital that discloses common interests between group members enhances individual information sharing with others (Wasko and Faraj, 2005). These common interests refer to "shared interests, goals, needs or practices", indicating that shared language or shared knowledge has profound impacts on the future of a community (Chiu et al., 2006). When consumers spend time communicating in a private space, they are apt to engage more in a public space because they use embedded social network resources in order to gain returns in expressive actions (Blanchard and Horan, 1998). These intangible resources are capitalized as relational social capital, which is exhibited across the contexts of social networking, brand-based community, and individual identity within a group (Huang et al., 2013). Consumer community enables group members to increase personal cognitions of shared language and shared vision and to build relationships based on trust, reciprocity, and identification (Blanchard and Horan, 1998; Bock et al., 2005; Chiu et al., 2006; Dholakia et al., 2004).

In a micro-level approach to SCE, consumer engagement is the core of the SCE paradigm. Engagement involves a series of emotional and behavioral activities such as information processing, reasoning, decision-making, and problem-solving and evaluating (Kearsley and Shneiderman, 1998; Huang et al., 2013). Scholars emphasize the emotional aspects of engagement by employing a cognitive framework adapted from schema theory, while others highlight the affective commitment to an active relationship with brand (Mollen and Wilson, 2010) or the flow experience (Csikszentmihalyi, 1990, 1997). The behavioral aspect of engagement substantiates a consumer's commitment in the social networking context in accordance with information seeking, information sharing and knowledge creating (Huang et al., 2013; Kearsley and Shneiderman, 1998). Consumer's 
information seeking behavior is often depicted as browsing for information in a digital context (Sismeiro and Bucklin, 2004). Information seeking includes individual searching as well as interactive searching (Sismeiro and Bucklin, 2004) which often explains "thirdparty" information searching (Wang et al., 2002). While information seeking behavior indicates the significance of information quality (Williamson, 1998), sharing interactions presents a process of relationship management (Bock et al., 2005; Huang et al., 2013). The capacity to share interactions is one determinant of the ability to sustain a digital community, thus creating a sense of belonging (Burnett, 2000; Teo et al., 2003). At the same time, the sustainability of digital community mutually drives system usage (Teo et al., 2003), allowing participants to share information while facilitating access to information, expertise, and ideas (Wasko and Faraj, 2005). In digital engagement, not only do consumers interact with each other, but they also provide knowledge (Clarke, 2010). Since new marketing incentives provide consumers with autonomy to produce technical, social, and cultural knowledge (Zwick et al., 2008), knowledge creation plays a key role in users' engagement in a digital environment.

SCE is characterized by three distinctive sets of actions. First, SCE concentrates on co-creating, sharing, and transforming value among consumers, businesses, and environments. For example, the structural capital in an interactive digital interface enables consumers to create any kind of information in Youtube (Ritzer and Jurgenson, 2010), and collaborative entries and knowledge in Wiki (Ritzer and Jurgenson, 2010) through storytelling, establishing authenticity, and developing personal connections (Aaker and Smith, 2010) through the digital web. Second, businesses pursue the seamless smart consumer experience through the integrated relational capital that offers limitless touch points and networks. For example, local stores can become showrooms for omnichannel shoppers who need to physically see and touch goods, return them, or have a face-to-face conversation with a store associate. Third, the cognitive capital through the combination of big data analytics and omni-channel distribution should be understood as multiple touch points in preemptively connecting with the consumer. This type of information is used for precision marketing, greater personalization, and heightened interactively with each customer in everything from cross-selling, upselling, and managing sales associates' time and behavior, to planning assortments, pricing, layout, and presentation (Lewis, 2014). Refer to Figure 3.

\section{The paradigm shift for fashion}

When enough significant anomalies accrue against a current paradigm, cumulative inconsistencies strain the existing structure to the point of collapse, and a crisis ensues (Lucas, 1985). Through trials with new ideas, a traditional paradigm is eventually supplanted with a new one. This scientific evolution is called a 'paradigm shift' (Kuhn, 1962). With a set of anomalies evident in the current TCE and GCE paradigms, this study offers the SCE model as a transforming paradigm for fashion that is evident through significant shifts in consumer, retail industry, and business strategies archetypes.

\section{Paradigm shift - fashion consumer}

Fashion consumers in TCE pursued a compilation of the many aspects of consumerbusiness interactions, each aspect contributing to coverall satisfactions. They seek 


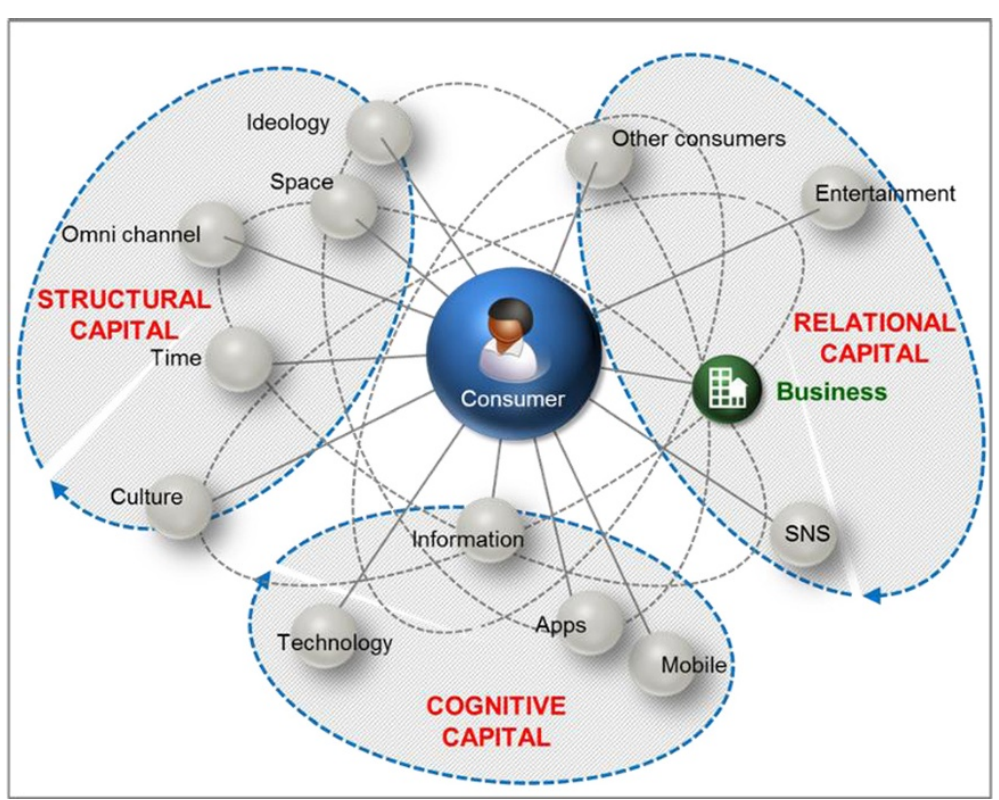

Figure 3 Social capital and interaction in Smart Consumer Experience.

entertainment and emotional stimulation throughout the shopping process, not just through the act of purchasing goods. This translates into not only demands for money, time, and energy savings, but also for pleasure from the shopping experiences (Kim et al., 2007). Consumer efficiency encompasses both benefit and cost components, reaches beyond the boundaries of product and service foci, and engages both utilitarian and hedonic principles of consumer behavior. Fashion consumers increasingly view the shopping activity itself as consumption, which leads to an evaluation of the entire shopping activity. Moreover, they seek a holistic shopping experience that is obtained via the shopping environment, its atmosphere, and the entertainment it offers (Kim et al., 2007).

GCE consumers are well-defined consumer segments that exhibit similar demographic and socio-cultural characteristics; share similar needs, tastes, and lifestyles; converge across national borders (Douglas and Craig, 1997; Ramarapu et al., 1999); and are not limited in consumption activities by geographic location (Globerman et al., 2001). Fashion consumers use the power of technology to form distinctive consumer clusters which connect across local norms, values, and identities. While they may not always be characterized by the same tastes or values; cluster members participate in a shared conversation (Holt et al., 2004). For example, GCE consumers enjoy Pinterest, one of the largest social networking services in which users can create and manage theme-based image Pinboards such as fashion, home, arts and crafts, food, events, interests, and hobbies. They can share photos by "re-pinning" Pinboards with other users and following other users' boards. Users also invite their friends to the Pinterest website which can be linked to a Facebook or Twitter profile so that Pinterest acts as a personalized media platform. Fashion retailers such as Gap, J. Crew, Ralph Lauren, Dillards and Nordstrom use Pinterest as an advertising platform to link their company to users with similar interests. Similarly, Polyvore is a social commerce website where users curate "sets" of products like fashion and home furnishing from a variety of online retailers 
and then share their creations with others. If consumers click on the products, they will get price and stock details and can directly access the site to make a purchase.

SCE consumers utilize smart devices or software that tailored to his or her specific consumer profile. Zite is a personalized intelligent magazine app for Android and iPad. It learns consumer's interest and reading habits and analyzes millions of articles each day to bring the consumers optimal matches for magazines, newspapers, authors, blogs, and videos that are completely tailored to his or her unique set of interests (Zite.com, 2013). For example, SCE consumers also co-create values and identities which are evident among global sustainable consumers as they seek socially responsible fashion brands. SCE consumers discover fair trade stores based on their location with the Fair Trade Finder app that lets them find, add, tag and photograph fair trade certified products wherever they are (Fair Trade USA, 2011). Conversely, GCE consumers purchase socially conscious clothing from internet-based retailers such as Edun, Easy ethical fashion.com, Fashion-conscience.com, and Adili, all of which are concerned with fairtrade and environmental impact and offer re-cycled and re-used apparel, organic materials and minimal packaging.

\section{Paradigm shift - fashion retail industry}

The magnitude of growth in consumer's digital engagement has had a tsunami effect on the fashion retail industry in the past decade. Conventional retailing is being inverted as consumers expect and create borderless shopping. From the growth of department stores in the 1960's and 1970's, to the 1980's retail expansion into catalogs, and the 1990's big box retail formats, the $21^{\text {st }}$ century has witnessed a new retail environment that shifted to value retailing. Fashion retailers who expanded their markets and extended their merchandise mix to broader and deeper product lines were able to move to the "Big Middle" (i.e., the marketspace in which the largest retailers compete in the long run) with e-commerce becoming the new frontier for innovation (Brown et al., 2005; Levy et al., 2005). These TCE transformational retail environments evolved to experiential retailing that subsequently led many retailers to recognize the need for shoppertainment, edutainment, and entertainment to create differentiation in their store environments and retail offerings (Kim et al., 2007).

While marketplace growth in the last half of the $20^{\text {th }}$ century was benchmarked by the extension of physical structures (e.g., building more shopping malls, retail stores, hotels, restaurants), the GCE marketplace is evolving into consumer-engaged marketspaces through global 24/7/365 digital access that links consumers to physical and virtual retail businesses. Worldwide e-commerce retail sales to consumers will grow to $\$ 1.86$ trillion by 2016, and 40.4 percent of global consumers made at least one online purchase in 2013, with expectations this will grow to 45.1 percent by 2017 (Davis, 2013). In the U.S., a recent Pew Internet and American Life Project Report (Pew research center, 2013) indicates that 91 percent of all American adults are part of a wireless, mobile population that participates in digital activities away from home or work and that 63 percent of adult cell phone owners in the U. S. use their phones to go online. This trilogy of mobile, digital and online networks creates a marketspace where retailers can test global-scale paradigms to drive new goods, service, and experience delivery systems.

In SCE, smart technology is the dominant medium for information exchange and it is accelerating the paradigm shift. The necessity for multiple distribution platforms 
beyond the Internet, mobile devices, and the physical store, is to be able to achieve preemptive distribution. Omni-channel creates an innovative and seamless consumer experience where consumers can start their journey in one channel and complete it in another through a continuous stream of activity that presents no barriers. Consumers want both responsive and adaptive interactions with content delivered in a way that best suits them as individuals and their particular device (The Guardians, 2013). A fully implemented omni-channel strategy seamlessly offers integrated and interchangeable distribution platforms for searching, shopping, ordering, purchasing, pickup, delivery, and returns. To achieve this, all operational points in the entire value chain must be seamlessly integrated and 'un-siloed' (Lewis, 2014). Successful examples of seamless integrated operations include Bonobos (Brooks Brothers), Top Shop (Nordstrom), and Sephora (JCPenney).

U.K. retailer Marks \& Spencer opened a new omni-channel store in Amsterdam as a clicks and bricks strategy. This e-boutique is a showplace with the world's first virtual rail. The rail is created by three 46-inch video screens and three physical rails of clothing, with constant updates, that showcase the latest trends. Customers can place orders for free delivery to the store through in-store order points and style advisers who are equipped with iPads. Customers are offered the latest fashions in a store with a smaller footprint and the shopping experience is brought with mobile and online sites (FierceRetail, 2013). The situational evolution of fashion retail access bound by time and space to its ubiquitous access is demonstrated by iBeacon and Brouha. These location-based technology apps deliver real-time retailer messages to customers. As customers shop in the store, they receive a stream of details about shopping deals and events, products, and other helpful timesensitive information directly to their devices (Morning News USA, 2013).

\section{Paradigm shift - fashion business strategies}

A convergence across national boundaries, prompted by global growth in income, travel, communication access, and entertainment, is reshaping consumer behavior through their exposure to diverse cultures and experiences. In TCE, market segments may be spatial when delineated by space boundaries, such as a shopping area, region or nation. In this form of "B2L2C(business to leader to consumer)" marketing (Nitto and Shiozaki, 2001), it is necessary to find relatively small groups and leaders who can influence group members and actively work with them in influence other group members. However, in the multi-attribute segmentation that is associated with GCE, access and information goes across segments. To optimize a multi-attribute segment group's on-demand expectations, the business strategy must accommodate the multichannel consumers who are expecting more personal utility from their devices such as mobile interfaces with brand web sites, coupon receipt and redemptions, and transactions (Mooney and Rollins, 2008).

As more consumers share information and ideas about their fashion interest, the fashion business strategies of GCE and SCE need to be engaged in the digital environment. Digital engagement has even positioned global consumers to take over product and service branding through cyber-branding structures (Javed, 2009). Further, social media, driven by one-to-one sharing of information and goods and services evaluations, is surfacing as a new consumer-driven cyber marketing tool.

Digital engagement also brings the hybridization of the consumer's role in the fashion retail industry. Hybridization offers a new GCE and SCE business model where companies 
source capital as well as develop products in cooperation with consumers. This approach is effective not only in reflecting consumer views and improving the quality of products developed, but also in enhancing the loyalty of consumers who participate in the development process (Nitto and Shiozaki, 2001). Topshop provided their customers with a special in-store and online experience through the campaign 'Wish you were at Topshop'. In this campaign customers received a free styling and make-up session and were invited to create their own digital 'Wish You Were at Topshop' postcard by using Instagram, an online photo and video-sharing social networking service. Customers shared their photo with friends both on and offline and also entered a competition for a chance to win a $£ 1,000$ summer shopping spree. As a result, the number of blog postings, views on Facebook, and comments exceeded a year's worth of Topshop's usual Facebook activity in just four days. Quirky, a crowd sourcing company uses interactions between the external online community and Quirky's internal team to launch new products in the marketplace. Community members can submit ideas or vote on which products Quirky will manufacture and sell. While Quirky sources product design from consumers, ZAOZAO sources production capital from consumers. ZAOZAO is a social retailer based on a crowd funding platform that allows consumers to discover new fashion designs and support emerging designers (Zaozao.com, 2013). Consumers browse and pre-order designs within a limited time period. As soon as all pre-orders are completed, a funded designer can produce the designs and consumers receive unique and limited-edition items as a reward for their support.

\section{Conclusion}

In 2013, over 2.7 billion people, 39 percent of the world's population, were using the Internet; a total of 31percent of this population was in the developing world compared to 77 percent in the developed world (ICT, 2013). By the end of 2014, it is expected that the global number of smartphones in use will reach 1.75 billion or one phone for every four people in the world (eMarketer.com, 2014). Emergence of this global technoeconomic system is challenging academia and the fashion industry. This study discusses three shifts in fashion paradigms by proposing the Total (TCE), Global (GCE) and Smart Consumer Experience (SCE) concepts derived from the concept of The Experience Economy (Pine and Gilmore, 1999), Consumer Culture Theory (Arnould and Thompson, 2005), Social Capital Theory (Putnam, 1995) and Digital Engagements (Mollen and Wilson, 2010; Csikszentmihalyi, 1990, 1997).

The consumer experience is a pervasive new value orientation that is transforming how consumers think, gain information, and make decisions about consumption activities to maximize their total experience value. Moreover, the experiences, products and services that consumers seek are being defined with a global and smart perspective that is made possible by boundary-free access to information and sourcing of products and services. Specifically, the Smart Consumer Experience avidly advocates consumer participation by leveraging the power of communities and networks and enabling consumers to influence retail businesses and co-create future marketspace values. This phenomenon has important implications for fashion consumers and fashion retail industry business strategies since fashion is an emulated behavior. This study demonstrates how consumers, the retail industry and business strategies are strategically contributing to this shifting fashion paradigm.

This shift in the fashion consumer paradigm has moved consumer expectations from the TCE value associated with extrinsic and intrinsic benefits and attached to product 
and service attributes to GCE experiential benefits. Consumer efficiency in TCE is based on a function of convenience, time, effort and financial resources while in GCE it includes holistic expectations for meaningful experiences. A consumer's cultural orientation, grounded in local norms, values, and identities in TCE, is being redefined in GCE as global consumer clusters that cross national and cultural boundaries. By employing smart devices or software that are uniquely tailored for each consumer, SCE offers a more consumer-centric approach than TCE and GCE. SCE consumers play key roles in value co-creation as well as pursue a diversified value orientation.

The fashion retail industry has shifted from an autonomous, primarily soft good product and service orientation in TCE, to integrated retailing concepts across global venues such as communication, entertainment, and transportation in GCE. The fashion retail marketplace in TCE is shifting from targeted to confluence across multiple segments in GCE. TCE and GCE consumers can shop multi-channels which offer choice among all physical and virtual formats and uni-channel which uses all channels during a single shopping episode in one retail format for a specific purchase. In SCE, consumers obtain what they pursue from an omni-channel environment that is supported by technology. Retail access, which previously was time and space bound, is now boundary free so that shopping with many retailers has become smart-ubiquitous.

Standardized fashion business strategies which evolved into customization in TCE and GCE are now moving into hybridization in SCE. Traditional information sources for fashion are being challenged by social networks and mass media in TCE while creating digital engagement in GCE and SCE. Strategies to create fashion brand image and identity that generated brand communities in TCE have expanded to fashion brand storytelling in GCE and consumer-brand synthesis in SCE. Fashion brand positioning became brand extension in TCE and moved into neo-tribalism where a brand is exalted over all other brands and diaspora where there is a migration of consumers to form new groups that are outside tradition consumption patterns.

Each paradigm presents distinctive features and reflects a different timeline according to its emergence in a global techno-economic system. However, the concept of a paradigm shift does not mean that all consumers who are active in this global techno-economic system are also engaged in SCE and that SCE is the only or best answer for the future. The experiences and roles of consumers in interactive environments will vary by product categories and the context in which they seek those products. The transformational fashion paradigm seeks what is often unpredictable progress over carefully controlled perfection, and it cultivates and assimilates consumers' unorthodox opinions or creative ideas, and makes permanent room for consumers and their communities in the decision circle. Successful businesses in fashion retail industry will operate under a new set of assumptions, including the notion that consumers will gladly ask for what they want, engage in ongoing dialogue and frequently share their options with the online public. And the fashion business strategy needs to engage the consumer through transparent communication, trust the consumer to co-create the business strategy, and then learn to be guided by impassioned consumer clusters. 


\section{Competing interests}

The authors declare that they have no competing interests.

Received: 29 May 2014 Accepted: 1 September 2014

Published online: 24 October 2014

\section{References}

ABI Research. (2013). 45 million windows phone and 20 million blackberry 10 smartphones in active use at year-end; enough to keep developers interested. Retrieved December 17, 2013 from https:/www.abiresearch.com/press/45million-windows-phone-and-20-million-blackberry.

Aaker, J, \& Smith, A. (2010). The dragonfly effect: Quick, effective, and powerful ways to use social media to drive social change. San Francisco, CA: John Wiley \& Sons.

Andrews, D. (2002). Audience-specific online community design. Communications of the ACM, 45(4), 64-68.

Arnould, EJ, \& Thompson, CJ. (2005). Consumer culture theory (CCT): Twenty years of research. Journal of Consumer Research, 31(4), 868-882

Bagozzi, RP. (2000). On the Concept of Intentional Social Action in Consumer Behavior. Journal of Consumer Research, 27(3), 388-396.

Berry, LL, \& Carbone, L. (2007). Build loyalty through experience management. Quality Progress, 40(9), 26-32.

Berry, LL, Carbone, LP, \& Haeckel, SH. (2002). Managing the total customer experience. MIT Sloan Management Review, 43(3), 85-89.

Belk, RW. (1988). Possessions and the extended self. Journal of Consumer Research, 15(2), 139-168.

Belk, RW, Sherry, JF, Jr, \& Wallendorf, M. (1988). A naturalistic inquiry into buyer and seller behavior at a swap meet. Journal of Consumer Research, 14(4), 449-470.

Binkley, C. (2013). More brands want you to model their clothes. The Wall Street Journal. Retrieved from http://online. wsj.com/news/articles/SB10001424127887324216004578483094260521704.

Blanchard, A, \& Horan, T. (1998). Virtual communities and social capital. Social Science Computer Review, 16(3), 293-307.

Bock, GW, Zmud, RW, Kim, YG, \& Lee, JN. (2005). Behavioral intention formation in knowledge sharing: examining the roles of extrinsic motivators, social- psychological forces, and organizational climate. MIS Quarterly, 29(1), 87-111.

Brown, JR, Dant, RP, Ingene, CA, \& Kaufmann, PJ. (2005). Supply chain management and the evolution of the "Big Middle". Journal of Retailing, 81(2), 97-105.

Burnett, G. (2000). Information exchange in virtual communities: A typology. Information Research, 5(4), Retrieved from http://informationr.net/ir/5-4/paper82.

Chang, H, \& Chuang, S. (2011). Social capital and individual motivations on knowledge sharing: Participant involvement as a moderator. Information \& Management, 48(1), 9-18.

Chiu, C, Hsu, M, \& Wang, ET. (2006). Understanding knowledge sharing in virtual communities: An integration of social capital and social cognitive theories. Decision Support Systems, 42, 1872-1888.

Cholachatpinyo, A, Padgett, I, \& Crocker, M. (2002). A conceptual model of the fashion process-part 1: the fashion transformation process model. Journal of Fashion Marketing and Management, 6(1), 11-23.

Clarke, N. (2010). Emotional intelligence and its relationship to transformational leadership and key project manager competences. Project Management Journal, 41(2), 5-20.

Coulter, RA, Price, LL, \& Feick, L. (2003). The origins of involvement and brand commitment: Insights from postsocialist central Europe. Journal of Consumer Research, 30(2), 170-183.

Cowan, K. (2012). Changing the face of retail: Where fashion meets technology. In The Guardian. Retrieved from http:/www.theguardian.com/media-network/media-network-blog/2012/may/16/retail-technology-decoded-fashion-2012.

Csikszentmihalyi, M. (1990). Flow: The psychology of optimal experience. New York: Harper and Row.

Csikszentmihalyi, M. (1997). Finding flow: The psychology of engagement with everyday life. New York: Basic Books.

Davis, D. (2013). A \$1.2 trillion global payday for e-commerce. Retrieved February 25, 2014 from http://www.internetretailer.com/2013/06/27/12-trillion-global-payday-e-commerce.

Dholakia, UM, Bagozzi, RP, \& Pearo, LRK. (2004). A social influence model of consumer participation in network- and small-group-based virtual communities. International Journal of Research in Marketing, 21(3), 241-263.

Douglas, SP, \& Craig, CS. (1997). The changing dynamic of consumer behavior: Implications for cross-cultural research. International Journal of Research in Marketing, 14(4), 379-395.

Emarketer.com. (2014). Smartphone user worldwide will total 1.75 billion in 2104. Retrieved February 24, 2014 from http://www.emarketer.com/articles/print.aspx?r=1010536.

Escalas, JE, \& Stern, BB. (2003). Sympathy and empathy: Emotional responses toadvertising. Journal of Consumer Research, 29(4), 566-578.

Evans, M. (1989). Consumer behavior towards fashion. European Journal of Marketing, 23(7), 7-16.

Fair Trade USA. (2011). Fair trade just a click away with new "Fair Trade Finder" app. Retrieved February 25, 2014 from http://fairtradeusa.org/blog/fair-trade-just-click-away-new-fair-trade-finder-app.

FierceRetail. (2013). Marks \& Spencer returns to Amsterdam with tiny Omnichannel Concept Store. Retrieved December 20, 2013 from http://www.fierceretail.com/story/marks-spencer-returns-amsterdam-tiny-omnichannel-concept-store/ 2013-07-24\#ixzz205UL0jRY

Firat, AF, \& Dholakia, N. (2006). Theoretical and philosophical implications of postmodern debates: Some challenges to modern marketing. Marketing Theory, 6(2), 123-162.

Fournier, S. (1998). Consumers and their brands: Developing relationship theory in consumer research. Journal of Consumer Research, 24(4), 343-373.

Fournier, S, \& Mick, DS. (1999). Rediscovering satisfaction. Journal of Marketing, 63, 5-23.

Globerman, ST, Roel, TW, \& Standiford, S. (2001). Globalization and electronic commerce. Journal of International Business Studies, 32(4), 749-769.

Gooderham, P, Minbaeva, D, \& Pedersen, T. (2010). Governance mechanisms for the promotion of social capital for knowledge transfer in multinational corporations. Journal of Management Studies, 48(1), 123-150. 
Grayson, K, \& Martinec, R. (2004). Consumer perceptions of iconicity and indexicality and their influence on assessments of authentic market offerings. Journal of Consumer Research, 31(2), 296-313.

Hirschman, EC, \& Holbrook, MB. (1982a). Hedonic consumption: Emerging concepts,methods, and propositions. Journal of Marketing, 46(2), 92-101.

Hirschman, EC, \& Holbrook, MB. (1982b). The experiential aspects of consumption: consumer fantasies, feelings, and fun. Journal of Consumer Research, 9(2), 132-140.

Holbrook, MB. (1987). What is consumer research? Journal of Consumer Research, 14(1), 128-132.

Holman, RH. (1980). Clothing as communication: an empirical investigation. Advances in Consumer Research, 7(1), 372-377.

Holt, DB. (1997). Poststructuralist lifestyle analysis: Conceptualizing the social patterning of consumption in postmodernity. Journal of Consumer Research, 23(4), 326-350.

Holt, DB. (2002). Why do brands cause trouble? A dialectical theory of consumer culture and branding. Journal of Consumer Research, 29(1), 70-90.

Holt, DB, Quelch, JA, \& Taylor, EL. (2004). How global brands compete. Harvard Business Review, 82(9), 68-75.

Huang, R, Kim, HJ, \& Kim, JY. (2013). Social capital in QQ China: Impacts on virtual engagement of information seeking, interaction sharing, knowledge creating and purchasing intention. Journal of Marketing Management, 29(3-4), 292-316.

ICT. (2013). The World in 2013 ICT Fact and Figures. Retrieved December 17, 2013 from http://www.itu.int/en/ITU-D/ Statistics/Documents/facts/lCTFactsFigures2013-e.pdf.

Javed, N. (2009). Meltdown creates new global champions. AH\&LA SmartBrief. Retrieved February 12, 2009 from http://www.4hoteliers.com/features/article/3759.

Karpen, IO, Bove, LL, \& Lukas, BA. (2012). Linking service-dominant logic and strategic business practice: A conceptual model of service-dominant orientation. Journal of Service Research, 15(1), 21-38.

Kearsley, G, \& Shneiderman, B. (1998). Engagement theory: A framework for technology based technology-based teaching and learning. Educational Technology, 38(5), 20-23.

Kim, HJ. (2012). Fashion-brand experience: Aligning brand equity approaches. Journal of Fashion Marketing \& Management, 16(4), 418-441.

Kim, HJ, Kim, JY, \& Huang, R. (2014). Social capital in virtual community: Impacts on the social shopping model for QQ China. Global Economic Review, 43(4), 3-24.

Kim, Y, Sullivan, P, \& Forney, JC. (2007). Experiential Retailing. New York, NY: Fairchild Publications, Inc.

Kozinets, RV. (2001). Utopian enterprise: Articulating the meaning of Star Trek's culture of consumption. Journal of Consumer Research, 28(1), 67-89.

Kozinets, RV. (2002). Can consumers escape the market? Emancipatory illuminations fromBurning Man. Journal of Consumer Research, 29(1), 20-38.

Kozinets, R, Sherry, JF, Jr, Storm, D, Duhachek, A, Nuttavuthisit, K, \& Deberry-Spence, B. (2004). Ludic agency and retail spectacle. Journal of Consumer Research, 31, 658-672.

Kuhn, T. (1962). The Structure of Scientific Revolutions. Chicago: University of Chicago Press.

Langerak, F, Verhoef, PC, Verlegh, PWJ, \& de Valck, K. (2004). Satisfaction and participation in virtual communities. Advances in Consumer Research, 31, 56-57.

Lee, I, \& Lee, K. (2012). Social shopping promotions from a social merchant's perspective. Business Horizons, 55(5), 441-451.

Levy, M, Grewal, D, Peterson, RA, \& Connolly, B. (2005). The concept of the "Big Middle". Journal of Retailing, 81(2), 83-88.

Lewis, R. (2014). In search of the future. retrieved January 7, 2014 from http://therobinreport.com/in-search-of-the-future/.

Lucas, C. (1985). Out at the edge: Notes on a paradigm shift. Journal of Counseling and Development, 64(November), 165-172.

Mascarenhas, OA, Kesavan, R, \& Bernacchi, M. (2006). Lasting customer loyalty: a total customer experience approach. Journal of Consumer Marketing, 23(7), 397-405.

Meyer, C, \& Schwager, A. (2007). Understanding customer experience. Harvard Business Review, 85(2), 116-126.

McAlexander, JH, Schouten, JW, \& Koenig, H. (2002). Building brand community. Journal ofMarketing, 66(1), 38-54.

McCracken, G. (1986). Culture and consumption: A theoretical account of the structureand movement of the cultural meaning of consumer goods. Journal of ConsumerResearch, 13(1), 71-84.

Mick, DG. (1986). Consumer research and semiotics: Exploring the morphology ofsigns, symbols, and significance. Journal of Consumer Research, 13, 196-213.

Mick, DG, \& Buhl, C. (1992). A meaning-based model of advertising experiences. Journal of Consumer Research, 19(3), 317-338.

Miller, CM, Mclntyre, SH, \& Mantrala, MK. (1993). Toward formalizing fashion theory Journal of. Marketing Research, 30(2), $142-158$.

Morning News USA. (2013). Apple Inc. Rolls Out Location-Based Technology iBeacon in Its Retail Stores. Retrieved December 20, 2013 from http://www.morningnewsusa.com/apple-inc-rolls-out-location-based-technology-ibeaconin-its-retail-stores-237177.html.

Mollen, A, \& Wilson, H. (2010). Engagement, telepresence and interactivity in online consumer experience: Reconciling scholastic and managerial perspectives. Journal of Business Research, 63(9-10), 919-925.

Mooney, K, \& Rollins, N. (2008). The open brand. Berkley: AIGA Design Press.

Muñiz, A, \& O'Guinn, TC. (2000). Brand communities. Journal of Consumer Research, 27(4), 412-432.

Muñiz, A, \& Schau, HJ. (2005). Religiosity in the abandoned Apple Newton brand community. Journal of Consumer Research, 31(4), 737-747.

Nitto, H, \& Shiozaki, J. (2001). Changing consumption patterns and new lifestyles in the $21^{\text {st }}$ century. NRI Papers, No. 24. Nomura Research Institute. Retrieved May 28, 2009 from http://www.nri.co.jp/english/opinion/papers/2001/pdf/ np200124.pdf.

O'Cass, A, \& McEwen, H. (2004). Exploring consumer status and conspicuousconsumption. Journal of Consumer Behaviour, 4(1), 25-39.

Oliver, RL, Rust, RT, \& Varki, S. (1997). Customer delight: Foundations, findings, and managerial insight. Journal of Retailing, 73, 311-336.

Peñaloza, L. (2000). The commodification of the American West: Marketers' production of cultural meanings at a trade show. Journal of Marketing, 64(4), 82-109. 
Peñaloza, L. (2001). Consuming the American West: Animating cultural meaning at a stock show and rodeo. Journal of Consumer Research, 28(3), 369-398.

Pew Research Center. (2013). Mobile technology fact sheet. Retrieved February 25, 2014 from http://www.pewinternet. org/fact-sheets/mobile-technology-fact-sheet.

Pine, BJ, \& Gilmore, JH. (1999). The experience economy. Cambridge, MA: The Harvard Business School Press.

Pine, BJ, \& Gilmore, JH. (2001). The experience economy. Health Forum Journal, 44(5), 10-16.

Putnam, R. (1995). Bowling alone: America's declining social capital. Journal of Democracy, 6(1), 65-78.

Ramarapu, S, Timmerman, JE, \& Ramarapu, N. (1999). Choosing between globalization andlocalization as a strategic thrust for your international marketing effort. Journal of Marketing Theory and Practice, 7(2), 97-105.

Rayport, JF, \& Sviokla, JJ. (1994). Managing in the Marketspace. http://hbr.org/1994/11/managing-in-the-marketspace/ar/pr.

Ritson, M, \& Elliott, R. (1999). Thesocial uses of advertising: An ethnographic study ofadolescent advertisingaudiences. Journal of Consumer Research, 26(3), 260-277.

Ritzer, G, \& Jurgenson, N. (2010). Production, consumption, prosumption: The nature of capitalism in the age of the digital 'prosumer'. Journal of Consumer Culture, 10(1), 13-36.

Rogers, EM. (1983). Diffusion of Innovations (3dth ed.). New York: The Free Press.

Scott, L. (1994). The bridge from text to mind: Adapting reader-response theory to consumer research. Journal of Consumer Research, 21(3), 461-480.

Sismeiro, C, \& Bucklin, RE. (2004). Modeling purchase behavior at an e-commerce web site: a task completion approach. Journal of Marketing Research, 41(3), 306-323.

Solomon, MR. (1983). The role of products as social stimuli: a symbolic interactionismperspective". Journal of Consumer Research, 10(3), 319-329.

Statista.com. (2014). Worldwide social commerce revenue from 2011 to 2015 (in billion U.S. dollars). Retrieved February 27, 2014 from http://www.statista.com/statistics/251391/worldwide-social-commerce-revenue-forecast/.

Teo, HH, Oh, LB, Liu, C, \& Wei, KK. (2003). An empirical study of the effect of interactivity on web user attitude. International Journal of Human-Computer Studies, 58(3), 281-305.

The Guardian. (2013). Omni-channel retail: joining up the consumer experience. Retrieved 20 December, 2013 from http://www.theguardian.com/media-network/media-network-blog/2013/jul/22/omni-channel-retail-consumerexperience.

Thompson, CJ. (1996). Caring consumers: Gendered consumption meanings and the juggling lifestyle. Journal of Consumer Research, 22(4), 388-407.

Valenzuela, S, Park, N, \& Kee, KF. (2009). Is there social capital in a social network site?: Facebook use and college students' life satisfaction, trust and participation. Journal of Computer-Mediated Communication, 14(4), 875-901.

Vargo, S, \& Lusch, R. (2008). Service-Dominant logic: Continuing the evolution. Journal of the Academy of Marketing Science, 36(1), 1-10.

Vargo, S, \& Lusch, R. (2006). Service-Dominant Logic: What It Is, What It Is Not, What It Might Be. In RF Lusch \& SL Vargo (Eds.), The Service-Dominant Logic of Marketing: Dialog, Debate, and Directions (pp. 43-57). Armonk, NY: M. E. Sharpe.

Vargo, S, \& Lusch, R. (2004). Evolving to a new dominant logic for marketing. Journal of Marketing, 68(1), 1-17.

Vehoef, PC, Lemon, KN, Parasuraman, A, Roggeveen, A, Tsiros, M, \& Schlesinger, LA. (2009). Customer experience creation: Determinants, Dynamics and management strategies. Journal of Retailing, 85(1), 31-41.

Wang, Y, Yu, Q, \& Fesenmaier, D. (2002). Defining the virtual tourist community: implications for tourism marketing. Tourism Management, 23(4), 407-417.

Wasko, MM, \& Faraj, S. (2005). Why should I share? Examining knowledge contribution in electronic networks of practice. MIS Quarterly, 29(1), 1-23.

Wellman, B, Salaff, J, Dimitrova, D, Garton, L, Gulia, M, \& Haythornthwaite, C. (1996). Computer networks as social networks: Collaborative work, telework, and virtual community. Annual Review of Sociology, 22(1), 213-238.

Williamson, K. (1998). Discovered by chance: The role of incidental information acquisition in an ecological model of information use. Library \& Information Science Research, 20(1), 23-40.

ZAOZAO.com. (2013). Retrieved December 21, 2013 from http://www.shopzaozao.com/about.

Zhang, Y, \& Hiltz, SR. (2003). Factors that influence online relationship development in a knowledge sharing community. Proceedings of the Ninth American Conference on Information Systems, 410-417.

Zite.com. (2013). Retrieved December 20, 2013 from http:/www.zite.com/

Zwick, D, Bonsu, SK, \& Darmody, A. (2008). Putting consumers to work: "Co-creation" and new marketing govern-mentality. Journal of Consumer Culture, 8(2), 163-196.

doi:10.1186/s40691-014-0015-4

Cite this article as: Kim et al: Shifting paradigms for fashion: from total to global to smart consumer experience. Fashion and Textiles 2014 1:15. 